\title{
Another look at age changes in geometric illusions
}

\author{
ALEXANDER W. PRESSEY and ALEXANDER E. WILSON \\ University of Manitoba, Winnipeg, Manitoba, R3T 2N2, Canada
}

\begin{abstract}
The method of production was employed to measure the Ponzo, filled space, parallel lines, and Baldwin illusions in children ranging in age from approximately 5 to approximately 10 years. The assimilative illusions (including the Ponzo) declined with age, whereas the contrast illusion increased with age. Girls tended to exhibit larger illusions than boys. It was argued that previous results on the Ponzo and Titchener circles illusions which showed an increase in illusion with age were not valid because of the use of inappropriate psychophysical methods.
\end{abstract}

Over 80 years have elapsed since Binet (1895) first posed and experimentally assessed the problem of whether there are any differences in the degree to which children and adults are susceptible to geometric illusions. Still, after a larger number of investigations, the basic facts are not clear. The Ponzo illusion, shown in Figures $1 \mathrm{~A}$ and $1 \mathrm{~B}$, provides an example of the kind of inconsistency that the data show. Leibowitz and his colleagues (Farquhar \& Leibowitz, 1971; Leibowitz \& Heisel, 1958; Leibowitz \& Judisch, 1967) have shown repeatedly that the Ponzo illusion increases with age, whereas research at the University of Manitoba indicates that the Ponzo effect decreases with age (Pressey, 1974).

There are several subtle differences in the procedures employed by the two sets of investigators, but none seems robust enough to produce the highly divergent trends. Initially, it was argued that the filled-space illusion was a confounding variable in the studies reported by Leibowitz, but the discrepancy remained when the filled-space illusion was removed. In addition, it was hypothesized that experimenter bias may have played a prominent role in producing the difference but, in retrospect, such an argument seems strained.

However, there is one hypothesis that does seem reasonable. The very young subjects may not have been following instructions and the psychophysical method that was employed may not have been sensitive to such bias.

The configuration employed by Leibowitz and his colleagues is shown in Figure 1A and the target used by Pressey is shown in Figure 1B. Subjects were required to compare the upper and lower horizontal lines and to say whether the bottom line was longer or shorter than the top line. Now, consider the possibility that some subjects did not understand what the word "line"

This study was supported by the National Research Council of Canada. We wish to express our appreciation to Neil Butchard for testing the subjects. Requests for reprints should be sent to the Department of Psychology, University of Manitoba, Winnipeg, Manitoba R3T 2N2, Canada. meant or that during the task they forgot that it was lines they were comparing. Assume also that they substituted the relatively undifferentiated task of choosing which area (top or bottom) was greater. Clearly, in the target employed by Leibowitz, the response based on area would be opposite to the response based on the Ponzo illusion. That is, a subject responding to the apparent size of the line would say "bottom smaller," but if he were responding to area he would say "bottom greater." The latter case would be interpreted as a "negative illusion" and would subtract from the measure of the Ponzo illusion. If it is also assumed that the probability of responding to area decreased with age (that is, older subjects understood instructions better), then the increasing Ponzo trend would be expected because fewer "negative illusions" would be exhibited.

Next consider Pressey's target in Figure 1B. If subjects were responding to area, response bias would result in "positive illusion" scores and thus add to the Ponzo effect. Young children would then be shown to have large illusions that declined with age (or as instructions became better and better understood). If the above interpretation is correct, then it must be concluded that neither Leibowitz's nor Pressey's data are valid.

The major aim of the present study was to eliminate (or at least decrease) the contribution of inappropriate responses, first, by differentiating the standard stimulus from the contextual stimuli in terms of color, and

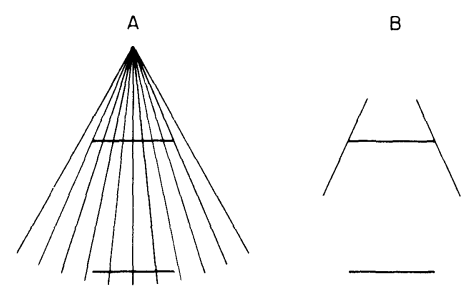

Figure 1. Two forms of the Ponzo configuration. 
second, by using the direct psychophysical method of production (Pressey, 1974) to provide a measure of illusion. It was of particular interest to determine whether the new procedure would verify the trends on the Ponzo and filled-space illusions found earlier in our laboratory.

A second aim was to measure age changes in the parallel lines illusion and a version of the Baldwin illusion with the method of production. These targets were chosen because they appear to be prototypes of assimilative and contrast illusions. For example, Pressey and Murray (1976) have argued that the parallel lines illusion provides the basic paradigm for assimilative illusions, and Restle and Merryman (1969) have argued that contrast is involved in the Baldwin configuration. In addition, Pressey (1974) has proposed the generalization that assimilative illusions decline with age and contrast illusions increase with age. Thus, the parallel lines and Baldwin configurations were included to assess age trends on the two types of illusions.

\section{METHOD}

\section{Subjects}

The subjects were 116 children drawn from one school in Winnipeg. One group consisted of 38 students with an average age of 5.5 years; a second group consisted of 38 students who had an average age of 7.5 years; and a third group consisted of 40 students who had an average age of 9.5 years. There was an equal number of males and females in each group.

\section{Materials}

All targets were drawn on $280 \times 215 \mathrm{~mm}$ sheets of white paper in which the standard line was drawn parallel to the narrow edge of the sheet and centered $90 \mathrm{~mm}$ below the top of the sheet. All standard lines were $50 \mathrm{~mm}$ long and $5 \mathrm{~mm}$ wide and were drawn in red ink. Since the method of production was employed, a red dot that served as a starting point was located in one of two positions. The "left" position was $100 \mathrm{~mm}$ below and $8 \mathrm{~mm}$ to the left of the left edge of the standard line, and the "right" position was $100 \mathrm{~mm}$ below and $8 \mathrm{~mm}$ to the right of the left edge of the standard line.

In the Ponzo illusion, the inducing lines formed an angle of $30 \mathrm{deg}$ at the (imaginary) apex. Each of the inducing lines was $100 \mathrm{~mm}$ long with a $25-\mathrm{mm}$ portion located above the standard line and a 75-mm portion below it. The extremities of the standard line just touched the inducing lines.

In the filled-space illusion, six $2 \times 3 \mathrm{~mm}$ black rectangles were equally spaced on the $50-\mathrm{mm}$ red line. In the parallel lines illusion, the contextual line was $70 \mathrm{~mm}$ long and was symmetrically located $3 \mathrm{~mm}$ below the standard line and parallel to it. In the Baldwin illusion, a 70-mm outline square was placed at the left edge of the standard line so that the standard line bisected the right edge of the square. The control line consisted of a single red horizontal line. All contextual features were drawn in black ink and, where the lines formed the contextual contours, they were $.5 \mathrm{~mm}$ wide. All targets were reproduced by high-quality commercial printing methods and were presented on a white target holder that was $368 \mathrm{~mm}$ wide and $395 \mathrm{~mm}$ high. The face of the holder was tilted backward $20 \mathrm{deg}$ in order to insure that the entire target was perpendicular to the line of sight. A chin rest was placed directly in front of the holder so that the distance between the subject's eyes and the face of the frame was about $41 \mathrm{~cm}$.

\section{Procedure}

Each subject was seated in front of the apparatus, placed his chin in the rest, and was shown a sample target drawn randomly from the population of targets. He was told that several pictures would be shown and each picture would contain a red line (which was pointed out) and a red dot (also pointed out). $\mathrm{He}$ was told that his task was to start at the red dot and draw a line that was equal in size to the standard line. The subject then made a practice response and a second target, chosen at random, was presented. The instructions were repeated, and, if it appeared that the instructions were understood, formal testing began. Each subject was tested twice in succession on each target, once with the left starting position and once with the right starting position. The order of starting positions was constant within subjects but was balanced between subjects. The targets were presented in random order to each subject. All responses were made with a sharp red pencil.

\section{RESULTS}

Responses were measured by a straight-edge scale and scores were accurate to within $.5 \mathrm{~mm}$. One striking feature of the results that was immediately obvious was that there were differences in the variability of scores in the three groups. Standard deviations were calculated for the five targets at each of the age groups and the results are shown in Figure 2. It is clear that betweensubjects variability decreased with age in all targets. This decrease is consistent with results reported previously by Wohlwill (1960) for a variety of perceptual tasks.

For purposes of graphic presentation, scores from the two trials were averaged to obtain a single score for each figure. Then the control score was subtracted from the score on the illusory target to obtain a measure of illusion. Finally, scores were averaged across subjects within each age group. The results, shown separately for males and females, are presented in Figure 3.

The data were analyzed by a multivariate analysis of covariance. There were four dependent variables (the four illusions) and one covariate (the control line).

A preliminary analysis of the data indicated that the assumption of homogeneity of regression lines was met. The test of parallelism of regression hyperplanes yielded an $F<1.00$, which indicated that the slopes of the dependent variables across the covariate did not vary reliably among the groups.

The next step in the analysis tested the interaction of age and sex. When adjusted for age and sex (Method 1,

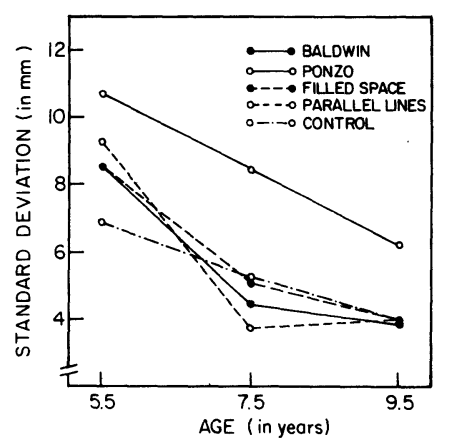

Figure 2. Variability of responses as a function of age. 


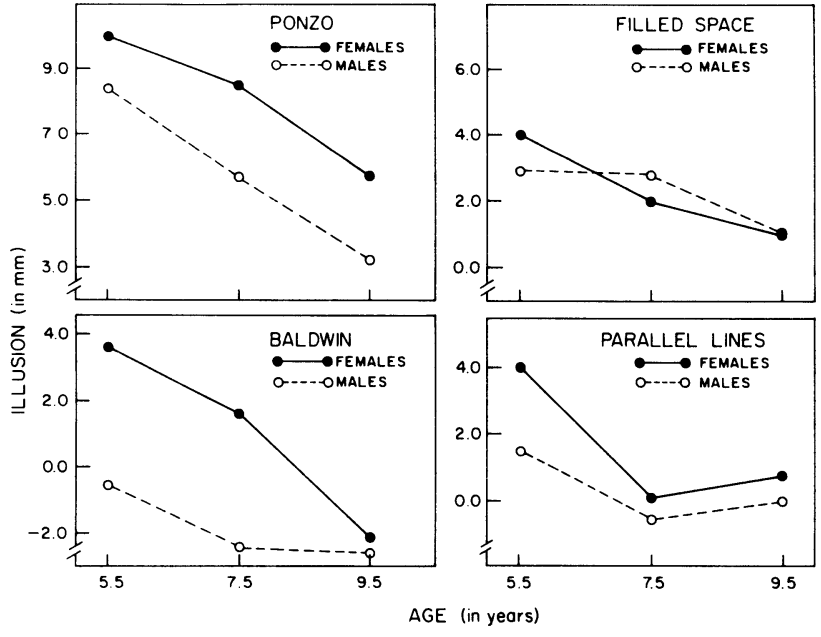

Figure 3. Age changes in the Ponzo, filled-space, Baldwin, and parallel lines illusions.

Overall \& Spiegal, 1969), the interaction was found to be not reliable $[F(8,212)=1.00, p=.86]$. It was concluded that the data conformed to an additive model and the Age by Sex interaction was pooled with the error term for the test of the main effects (Kirk, 1968).

\section{Sex}

Multivariate analysis of covariance revealed that sex, when adjusted for age, was marginally reliable $[F(4,108)=1.96, p=.10] .{ }^{1}$ Univariate analyses indicated that the sex difference was significant only for the Baldwin figure $[F(1,111)=6.01, p=.015]$.

Age

When adjusted for sex, age was found to be a reliable factor $[F(8,216)=1.95, p=.054]$. Trend analysis indicated that the linear component of age was reliable $[F(4,108)=2.70, p=.034]$ after adjusting for the quadratic component. However, the quadratic component was not reliable after adjusting for the linear component $[\mathrm{F}(4,108)=1.24, \mathrm{p}=.30]$.

\section{DISCUSSION}

The decline in the Ponzo illusion with increasing age supports the trend obtained previously in our laboratory and contradicts the results obtained by Leibowitz and his co-workers. Since the decline has been obtained by two different psychophysical methods, it is tempting to conclude that the increasing trend is due to the use of a psychophysical method that allows a large response bias to operate. And certainly, any method that requires a dichotomous response, with the consequent statistical estimate of the point of subjective equality (PSE), seems susceptible to error. In other words, when the subject says, for example, "bottom," it is difficult to know whether he means bottom line longer, bottom line shorter, bottom area larger, bottom area smaller, or whatever. And although one can never be certain that any psychophysical method can completely eliminate such errors, with a direct method such as the method of production, one can examine each response and estimate whether subjects understood instructions. Thus, on occasion we have had very young children repeatedly draw lines from the dot to the edge of the sheet. In such a case, there was no doubt that the task was not understood and that, therefore, the data were invalid.

The possibility that psychophysical methods based on dichotomous responses are inappropriate when young children are tested throws into question the age trends that have been found for the Titchener circles illusion by Wapner, Werner, and Comalli (1960) and by Weintraub and Cooper (1972). Wapner et al. used the two forms of the Titchener circles illusion simultaneously (see Figure 4); that is, the test circle was flanked by small circles and the comparison circle was flanked by large circles. Now, on the assumption that many young subjects responded to area rather than to the test and comparison circles, there would be many responses such as "right larger," which, in Figure 4, corresponds to a negative illusion. If, then, the frequency of these "negative illusions" declined with age, an age trend of increasing illusion would result.

Weintraub and Cooper's (1972) target is shown in Figure 5, in which the test circle is flanked by larger circles and compared to a single comparison circle. On the hypothesis that the young subjects respond to area, there would be many responses such as "right smaller," which again corresponds to a "negative" illusion. The reduction of such negative illusions would result in a trend of increasing illusion.

The hypothesis that the increasing age trends found in the Titchener circles illusion are not valid leads to some understanding of data obtained by Sigurdson (1974). She employed the method of adjustment (Pressey, 1977) to measure the Titchener circles illusion and, for the figure flanked by small

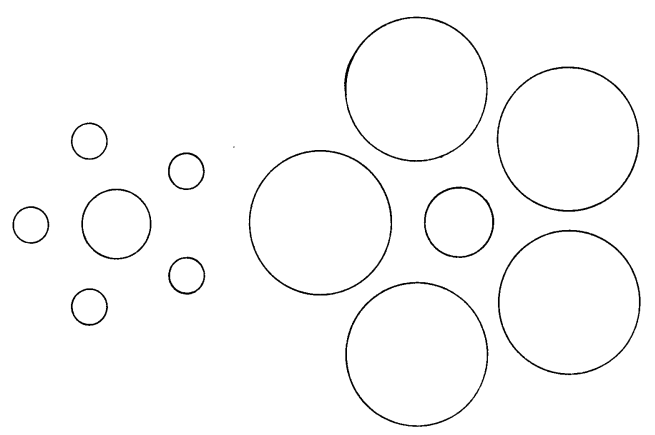

Figure 4. Version of target employed by Wapner and Werner (1957) to measure Titchener circles illusion.
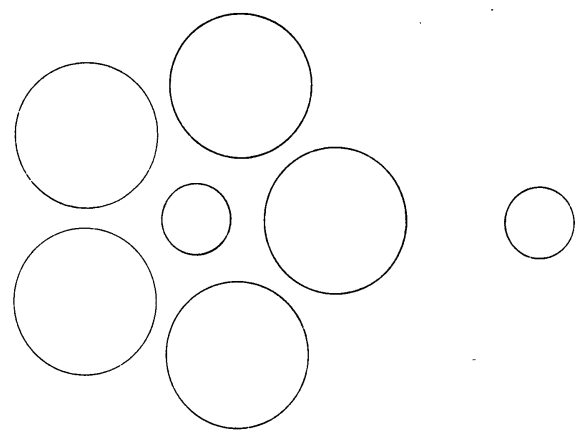

Figure 5. Version of target employed by Weintraub and Cooper (1972) to measure Titchener circles illusion. 
circles, she obtained an expansion illusion that exhibited a statistically significant decline with age. Thus, there is good reason to believe that the age trend on the Titchener circles illusion is not of the type reported by previous researchers, and it is necessary to repeat these studies using more sophisticated psychophysical methods.

One of the objectives of this study was to determine whether there are different age trends for assimilative and contrast illusions, as was hypothesized by Pressey (1974). The results showed that all three assimilative illusions (the Ponzo, filled space, and parallel lines) declined with age. The Baldwin illusion, which was chosen to exemplify contrast, did indeed increase with age for the boys, but for girls an assimilative illusion was present at the early ages, and this assimilative effect declined with age. On the whole, these results support the generalization that assimilative illusions decrease with age and contrast illusions increase with age (Pollack, 1964; Pressey, 1974; Quina \& Pollack, 1972; Santostefano, 1963).

The sex difference found in this study is also of interest because it is consistent with data reported previously. For example, Pressey and Sweeney (1970) found that girls had a larger Poggendorff illusion than boys; Fraisse and Vautrey (1956) reported a similar trend on the vertical-horizontal illusion, and Sigurdson (1974) obtained a similar difference on the Delboeuf illusion. However, reliable sex differences are generally not reported when adult populations are employed (e.g., Clem \& Pollack, 1975), and it may be that sex differences disappear in adulthood. On the other hand, it may be that the lack of a sex difference is due to the fact that most studies on visual illusions are carried out using university students. Studies on age changes, on the other hand, employ samples that are more representative of the population as a whole. Thus the sex difference may be related in some complex way to intellectual ability. At any rate, the facts about sex differences in visual illusions are still not well understood.

\section{REFERENCES}

Binet, A. La mesure des illusions visuelles chez les enfants. Revue Philosophique, 1895, 40, 11-25.

Clem, R. K., \& Pollack, R. H. Illusion magnitude as a function of visual field exposure. Perception \& Psychophysics, $1975,17,450-454$.

FARQUHAR, M., \& LeIBowitz, H. W. The magnitude of the Ponzo illusion as a function of age for large and small stimulus configurations. Psychonomic Science, 1971, 25, 97-99.

Fraisse, P., \& Vautrey, P. The influence of age, sex and specialized training on the vertical horizontal illusion. Quarterly Journal of Experimental Psychology, 1956, 8, 114-120.

Gabriel, R. M., \& Hopkins, K. D. Relative merits of MANOVA, repeated measures ANOVA and univariate ANOVAs for research utilizing multiple criterion measures. The Journal of Special Education, 1974, 8, 377-389.
KIRK, R. E. Experimental design: Procedures for the behavioral sciences. Belmont, Calif: Brooks/Cole, 1968.

Leibowitz, H. W., \& Heisel, M. A. L'evolution de l'illusion de Ponzo en fonction de l'age. Archives de Psychologie, 1958, 36, 328-331.

LEIBowitz, H. W., \& Judisch, J. A. The relation between age and the Ponzo illusion. American Journal of Psychology, 1967, 80, 105-109.

Overall, J. E., \& Spiegel, D. K. Concerning least squares analysis of experimental data. Psychological Bulletin, $1969,72,311-322$.

Pollack, R. H. Simultaneous and successive presentation of elements of the Müller-Lyer figure and chronological age. Perceptual and Motor Skills, 1964, 19, 303-310.

Pressey, A. W. Age changes in the Ponzo and filled space illusions. Perception \& Psychophysics, 1974, 15, 315-319.

Pressey, A. W. Measuring the Titchener Circles and Delboeuf illusions with the method of adjustment. Bulletin of the Psychonomic Society, 1977, 10, 118-120.

Pressey, A. W., \& Murray, R. Further developments in the assimilation theory of geometric illusions: The adjacency principle. Perception \& Psychophysics, 1976, 19, 536-544.

Pressey, A. W., \& Sweeney, O. Age changes in the Poggendorff illusion as measured by a method of production. Psychonomic Science, 1970, 19, 99-100.

Quina, K., \& Pollack, R. H. Effects of test line position and age on the magnitude of the Ponzo illusion. Perception \& Psychophysics, 1972, 12, 253-256.

Restle, F., \& Merryman, C. Distance and illusion of length of line. Journal of Experimental Psychology, 1969, 81, 297-302.

Santostefano, S. A developmental study of the Delboeuf illusion. Perceptual and Motor Skills, 1963, 17, 23-29.

SigurDson, E. The effects of culture and environment on assimilation and contrast illusions. Unpublished Master's thesis, University of Manitoba. 1974.

WaPNer, S., \& Werner, H. Perceptual development. Worcester: Clark University Press, 1957.

Wapner, S., Werner, H., \& Comalli, P. E. Perception of part-whole relationships in middle and old age. Journal of Gerontology, 1960, 15, 412-415.

Weintraub, D. J., \& Cooper, L. A. Coming of age with the Delboeuf illusion: Brightness contrast, cognition, and perceptual development. Developmental Psychology, 1972, 6, 187-197.

WoHLwill, J. F. Developmental studies of perception. Psychological Bulletin, 1960, 57, 249-298.

\section{NOTE}

1. A more liberal criterion than the traditional .05 level was adopted because multivariate analysis is a conservative test (Gabriel \& Hopkins, 1974).

(Received for publication July $11,1978$. 